\title{
Cluster Model of Inter-Subject Interactions in Agro-Food Complex
}

\author{
Makarevich L.O.* \\ Chair of System analysis and information processing \\ Kuban State Agrarian University \\ Krasnodar, Russia \\ paragon_lily@mail.ru
}

\author{
Ulez'ko A.V. \\ Chair of Information support and modeling of economic \\ systems in agriculture \\ Voronezh State Agrarian University \\ Voronezh, Russia \\ arle187@rambler.ru
}

\author{
Reimer V.V. \\ Faculty of Finance and Economics \\ Far Eastern State Agrarian University \\ Blagoveshchensk, Russia \\ valer-ken@rambler.ru
}

\begin{abstract}
Agro-industrial integration is a classic case of vertical integration associated with ensuring the interaction of economic entities operating at different stages of the formation of the final product values in the agri-food complex. It is proposed to consider sets of incentive causes, constraints and risks, directions, types, and forms of integration as the essential characteristics of vertical agro-industrial integration. The cluster model for the integration relation development is considered the most promising form of development of agri-food systems, and clusters are viewed as the optimal tool for creating the system of inter-subject relations between participants in the agro-industrial integration interacting within the boundaries of localized economic areas. The use of the advantages of territorial concentration and the possibility of establishing strong and longterm formal and informal relations among the economic integration subjects objectively determine higher flexibility of cluster structures and the efficiency of functioning of all their elements.
\end{abstract}

Keywords - integration; vertical integration; agro-industrial integration; integrated formations; economic clusters.

\section{INTRODUCTION}

Agro-industrial integration is a natural way of interaction between economic entities, economically, technologically and organizationally united in a single product chain, covering all of their links: from the production of agricultural raw materials to the production and sale of final products. The specific form of agro-industrial integration is being selected by economic entities based on the strategic goals of economic interaction, current economic interests, financial situation, development of the technical and technological base, innovation potential, the level of competition in the local markets, the possibility of participating in the special-purpose programs, and gaining access to governmental support funds, etc. The purpose of the research is to reveal the essential characteristics of the key forms of interaction between subjects of agro-industrial integration.

\section{RESEARCH RESULTS}

The process of public production is a combination of continuous interactions of economic agents associated with the need to realize their economic interests.

The forms of interaction among business entities are determined by the type of production relations dominating in society and the level of productive forces development, the technical and technological basis of which objectively determines the level of division of labor and production specialization and the ways of its cooperation and integration, forming the conditions for technological, organizational, and economic interaction and the environment of intra-system and inter-system relations regarding the production, exchange, distribution, and consumption of collective goods.

Interactions are a stable system of behavior of integrating economic entities with certain properties, to which it is proposed to include:

- objectivity of the technological, economic, and organizational interactions of heterogeneous subjects;

- possibility of coordination of their common and individual development targets;

- coordination of the behavior of the interacting subjects in time and space;

- predictability and rationality of the behavior of the interacting subjects and their reactions to standard impulses (information influences);

- existence of the common system for integration motivation and realization of the necessity of the balance of the interests of the interacting subjects;

- existence of the single economic space which allows ensuring the stability of the links among the interacting subjects, etc. 
The integration relations are traditionally considered in the context of three components: technological, economic and organizational. If the technological component of integration relations is associated with ensuring the full cycle of the reproduction process (agricultural production, transportation, refinement, storage, processing and sale of final products), then the economic component is associated with the formation, distribution and redistribution of income among all subjects of integration relations, while the organizational component aimed at ensuring the conditions for their effective interaction.

In the theory of integration, it is customary to distinguish between horizontal and vertical integration. If vertical integration is an inter-sectoral interaction of economic entities "along" the value chain, then horizontal integration suggests their interaction at the level of individual links of these chains (within industries), which allows optimizing the processes of labor division and deepen production specialization.

The main reasons for the initiation of vertical integration processes are, as a rule, the following: a desire to realize the individual interests of diverse types of interacting business entities; establish control over the activities of counterparties; form closed product chains; form stable intersubjective relationships; simplify the system of intersubjective interactions; create sustainable competitive advantages; ensure the effect of concentration of capital and production; strengthening the market position; optimization of cash flows, resource support, taxation; reduction of distribution costs, etc.

At the same time, there are certain limitations and risks that to some extent hinder the processes of vertical integration. These include: objective complication of the management system and increase in managerial costs; increase in investment costs; reduction in adaptive capacities when development conditions change; the need to ensure a given level of efficiency at all stages of integration; restriction on the freedom of choice of counterparties; complication of the distribution of efforts and resources; the threat of structural degradation of the assets; complexity of logistics functions, the growth of volumes and intensity of the information flows, etc.

The initiators of the integration processes, as a rule, are entities that implement the functions of processing agricultural products and solve the problem of creating sustainable resource zones. In this regard, it is their interests that are fundamental when choosing specific forms of agro-industrial integration and integration interactions, but the sustainability of the development of integrated formations will be determined by the ability of the integrator to ensure a balance of interests of all participants in integration relations.

Integration relations are characterized by stability and, unlike random market interactions, suggest the emergence of certain forms of cooperation among the stably interacting entities that reflect the specifics of the organization of integration processes, and mechanisms of inter-subject interactions that ensure the coordination of economic entities and the realization of their individual interests as a result of establishing sustainable economic, organizational, technological, and other types of relationships.
At each stage of development of the public production system, only the forms of integration interactions dominate that ensure the totality of integrating entities minimizing transaction costs and maximizing the value of economic benefits. Moreover, the process of distribution and redistribution of value added was determined by the mechanism that is being formed within the framework of a specific economic formation and is adequate to the established method of production and the level of development of production relations.

Agro-industrial integration is a classic case of vertical integration associated with ensuring the interaction of economic entities operating at different stages of the value formation for the final products of the agri-food complex. Various length and level of complexity of the main product and technological chains inherent in the agri-food complex determine the specifics of the organization of inter-subject interactions of integrating subjects [1-9].

The subjects of intra-system interactions within the framework of agricultural integration are determined by:

- the state, as the initiator and macro regulator of the processes of the agro-food complex functioning;

- business entities of the agrarian sector, from large integrated forms and agricultural organizations to small farms and personal subsidiary plots;

- business entities of the food and processing industry, integrated with agricultural producers in the framework of various food chains and using various forms of interaction with them;

- $\quad$ subjects of industrial infrastructure that implement the functions of industrial support for agricultural activities of economic entities of the agricultural sector (maintenance, transportation, storage, primary jobs, construction, etc.)

- subjects of market infrastructure that implement the functions of sale and supply assistance for business entities and bringing the produced goods to the final consumer;

- scientific and educational organizations creating the sub-system of staff and scientific provision for the agro-food complex development processes.

Organization of integration interactions should be based on the following provisions:

- the interaction of economic entities is based on their interests, the need for the implementation of which initiates the emergence of inter-subjective relations and determines the form of their existence;

- integration is a way of interaction of economic entities, occurring due to the presence of the stable causal dependence of the emergence of cooperation relations;

- integration interactions are considered as a form of relations between economic entities interacting within the framework of value added chains; 
- the influence of the economic entities on the development processes through a stable system of inter-subjective relationships and links that determine the way to coordinate their activities;

- integration interactions are realized in the form of a reaction of integrating entities to impulses, through which they have a targeted effect on each other;

- one of the key properties of integration interactions is their stability, which ensures the integrity of integration formation over a relatively long time horizon;

- the stability of integration interactions is determined by the capabilities of interacting entities for the implementation of their individual economic interests;

- the heterogeneity of business entities, representing various links in the value chain and having different interests, necessitates the organization of both intraindustry and inter-industry interactions;

- the system for organizing integration interactions implies the existence of certain standards that determine the expected typical reactions of subjects to typical informational influences, and the "rules of the game" accepted by all interacting entities;

- the integration of equal entities autonomously functioning at the same level of value chain and having the ability to independently make all key decisions occurs on the basis of the horizontal interactions;

- the integration of entities representing various links in the value chain and characterized by the presence of entities with dominant interests that determine the standards and conditions of interaction, making key decisions for the development of integration associations, is realized through the vertical interactions;

- the consolidation of entities involved in the value chain in the framework of the development of equal partnerships, which allow balancing individual interests and maximizing the system-wide synergetic effect through the use of "soft" forms of integration links and special coordination mechanisms, is carried out on the basis of network-type interactions;

- the form of integration interactions reflects the way of organizing the integration of technologically, economically, and organizationally interrelated economic entities within the framework of value added and income distribution chains;

- $\quad$ at each stage of development of the public production system, only the forms of integration interactions dominate that ensure the totality of integrating entities minimizing transaction costs, maximizing the value of economic goods, and effectiveness of the entire value chain;

- the formation of a specific form of integration interactions, as a rule, is a subject that occupies a dominant position in the value chain, seeks to minimize its transaction costs and in a certain way insure itself against the possible opportunistic behavior of its counterparties;

- in the event that counterparties are economically unstable and can not ensure the stability of the functioning of multi-link value chains, the dominant entity in the chain begins the processes of absorption of weaker entities, implementing the corporate integration model, giving priority to its own economic interests;

- if the economic situation of the entities located at the lower levels of the value chain is relatively stable, their activity is efficient, and market influence is strong enough, then the dominant actors in the chains are forced to make certain compromises and look for the forms of organization of integration interactions that provide attractive cooperation and the possibility of maximizing the realization of the interests of each subject, integrated into a certain technological chain;

- the variety of types and forms of integration interactions objectively necessitates the formation of special mechanisms to ensure both vertical and horizontal coordination of actors, as well as the interaction of elements and sub-systems that form the organizational structure of economic entities themselves.

It is customary to consider territorial product clusters as a promising form of organizing the interaction of agro-industrial entities, within which integration relations reach a fundamentally different level as a result of the emergence of conditions ensuring the mutually beneficial cooperation of integrating entities and the realization of their economic interests on the basis of a fundamentally different system of intersubjective relations and "soft" effect of the state in the intra-cluster interaction processes [10-15].

Many researchers consider the cluster model of integration relation development as the most promising form of development of agro-food systems and proclaim the clusters as the best tool for forming a system of inter-subject relations of agro-industrial integration participants interacting within the boundaries of localized economic spaces.

The generalized subject of the theoretical study of economic clusters is the connections and interdependencies of participants in the value formation chains that objectively exist as a result of the division of labor and specialization of economic entities at various stages of these chains, but which go beyond the framework that has already become traditional horizontal network structures operating within individual territories or industries.

The use of the cluster approach makes it possible to identify the entire set of business entities interested in joining separate clusters and to implement mutually beneficial forms of integration relationships that are impossible under other forms of integration.

The cluster approach in its essential understanding should be considered as a fundamentally new way of organizing 
economic systems and their structuring. The implementation of this approach is associated with the need to comply with several fundamental principles:

- the clustering process involves the formation of a strategic set of economic entities that complement each other in the process of forming a value chain and are concentrated within the boundaries of territorially localized economic spaces;

- the development of economic entities integrating within the cluster involves the selection of the main industry (product) and associated segments, technologically and organizationally complementing the basic activity;

- the clustering is based on the consolidation of individual interests of competing economic entities through the development of horizontal integration relations, which allows concentrating resources and efforts in solving the problem of overcoming systemic barriers that are the obstacle to the development of the entire cluster structure and its individual elements;

- the clustering suggests the active participation of the state in managing the development of cluster structures in terms of the use of various forms of public-private partnerships in the framework of ensuring the sustainability of the territorial development that form the spatial basis of integrated cluster-type formations;

- the clustering is associated with the localization of economic spaces, the boundaries of which are set based on their territorial, technological and institutional limits;

- the clustering provides for minimization of sectoral, technical-technological, reproduction and other imbalances existing in the sectoral, technological and reproduction structure of economic systems of various levels;

- the clustering involves the formation of effective adaptation mechanisms to ensure the flexibility of cluster formations and their adequate response to fluctuations in the functioning environment;

- the clustering ensures the growth of multiplicative effects due to the achievement of the balance of economic interests of the participants of cluster formations, improving the quality of intersubjective relations, carrying out united innovation and technicaltechnological policy, increasing market influence, etc.;

- it is impossible to create an economic cluster by administrative methods, cluster type interactions occur naturally when conditions arise that make it economically feasible to modernize relations between economic entities of interrelated industries and create a unified infrastructure support system;

- the cluster formations are a "soft" form of integration, ensuring the preservation of the organizational and functional structure of integrating subjects, but ensuring the emergence of synergistic effect by increasing the efficiency of interaction among subjects at all links in the food chains.

The study of the processes of the genesis of economic clusters suggests that most of them are formed within the framework of the evolution of economic systems and ensure that the level of development of intersubjective relations in the interrelated industries in localized economic spaces corresponds to the level of development of productive forces and production relations. If at the first stage, the creation of a raw material agglomeration is considered as the goal of developing vertical integration and then at the second stage (development of horizontal integration relations) interaction with such structures is provided. At the third stage, the main objective is connected with the improvement of the market position of the subjects of cluster interaction, at the fourth with the creation of an effective resource support system, and at the fifth - with the formation of a system of scientific and personnel support of the cluster. In modern conditions all these stages can occur simultaneously.

\section{CONCLUSION}

Agro-industrial integration is a priority for the development of the Russian agro-food complex, ensuring the effectiveness of economic, organizational and technological interactions of producers and processors of agricultural products. The most essential characteristics and properties of agricultural and food systems and various forms of organization of integration relations are manifested at the regional level, when the scale of production and localized economic spaces allows identifying all their specific elements and the features of production-technological and organizational-economic interactions. It is at the regional level that the possibility of maximizing the level of efficiency of inter-sectoral and inter-subject interactions and the realization of the advantages of each form of interaction between subjects of agro-industrial integration are provided.

\section{References}

[1] J.N. Severina, A.V. Ulezko, "Specifics of agro-industrial complex as a management object", Econ. of agricult. in Russ., no. 9, pp. 54-61, 2017.

[2] P. Sovetov, Agro-industrial integration: concepts, mechanisms, efficiency. Publ. house of Kolsky sci. center of Russ. Acad. of Sci., 2007, 117 p

[3] O.A. Rodionova, "Stimulating and impeding factors for agri-food sector integration development”, Agrar. Bull. of Ural, vol. 62, no. 8, pp. 25-28, 2009

[4] K.S. Ternovykh, N.G. Nechaev, A.A. Izmalkov, Agro-industrial integrated formations: state and development prospects, Monograph. Voronezh: VSAU, 2013, 245 p.

[5] K.S. Ternovykh, N.G. Nechaev, "Development of the integrated structures in the agro-industrial complex: problems of solution stages", Econ. of agricult. and proc. companies, no. 8, pp. 53-56, 2012

[6] E.O. Kydyrbayeva, B.K. Shomshekova, B.H. Kylyshbayeva, S.S. Bisenova, "Development of cluster integration in agricultural sector of the republic of Kazakhstan", Int. J. of Econ. and Financial Issues, vol. 5, no. 6, pp. 65-71, 2016

[7] I.N. Sycheva, I.A. Svistula, "Cross-sectoral approach to improving integration processes in agro-industrial complexes", Espacios, vol. 38 no. 33. p. 6,2017

[8] N. Gorshkova, L. Grigoryeva, P. Perekhodov, E. Shkarupa A. Arkannikov, "Informational and analytical support for integration of 
agro-industrial enterprises in Russia”, Russia and the European Union. Development and Perspectives. Cham, Switzerland, 2017, pp. 399-405.

[9] L.V. Popova, T.A. Dugina, A.V. Malofeev, I.S. Korabelnikov, E.A. Likholetov, "Influence of integration processes on economy of the agroindustrial complex: a view from the positions of various models of economic systems", Lecture Notes in Networks and Syst., vol. 57, pp. 3-9, 2019.

[10] M. Kranjac, U. Sikimić, M. Vujaković, I. Molnar, "Cross border protection of the clusters' intellectual property in the agricultural sector", Agricult. Econ., no. 61, pp. 23-30, 2015.

[11[ O. Borisova, L. Abramova, L. Zageeva, E. Popkova, I. Morozova, T. Litvinova, "Role of agricultural clusters in provision of food security”, Europ. Res. Studies J., vol. 3, no. 18, pp. 287-298, 2015.
[12]. E. Popkova, T. Litvinova, N. Saveleva, V. Sarakhmanova, T. Popova, S. Mayer, "Problems and perspectives of formation of agricultural clusters for increasing food security of developing countries", Europ. Res. Studies J., vol. 18, no. 3, pp. 177-186, 2015.

[13] T.V. Savchenko, A.V. Ulez'ko, N.N. Kravchenko, A.A. Tyutyunikov, "On the prospects of agro-industrial clusters formation", Res. J. of Pharmac., Biolog.l and Chem.1 Sci., vol. 5, no. 5, pp. 1790-1795, 2014.

[14] T.A. Pechenegina, "Fformation of the economic clusters as the impulse of economic growth", Int. J. of Appl. Busin. and Econ. Res., vol. 14, no. 14, pp. 727-734, 2016.

[15] Y.V. Matveev, I.A. Lunin, O.V. Trubetskaya, P. Rousek, V.A. Kopnov, "Clusters and their role in economic development", Int. J. of Econ. Perspect., vol. 10, no. 3, pp. 113-125, 2016. 